\title{
TECHNOLOGY FOR SYNTHESIS OF GROUP DECISIONS IN VEHICLE SELECTION PROBLEM FOR MULTI-MODAL TRANSPORTATION
}

\section{Igor Kovalenko ${ }^{1}$ \\ Alyona Shved ${ }^{2}$}

DOI: https://doi.org/10.30525/978-9934-588-15-0-57

\begin{abstract}
Currently, multimodal transport is one of the priorities of the Ukrainian and European transport policies. The multimodal logistics is based on the effective management of technologically interconnected transportation of goods using more than two modes of transport under a single transportation contract. World practice of using multimodal logistics systems shows that today multimodal transportation is the most popular way to transport goods over medium and long distances. Based on effective combination of modes of cargo transportation, this approach can significantly reduce the cost of transportation, reduce the transportation time and organize the transportation of goods to anywhere in the world. However, using such kind of transportation is associated with various kinds of uncertainty and risks, caused by unevenness of material and traffic flows, using of various modes of vehicles, deterioration, obsolescence of transport infrastructure, etc. This gives rise to a wide range of tasks, solution of which is lain in the application of methods of decision support, forecasting, optimization of logistics systems and the construction of applied information technologies on this basis. At the same time, it is necessary to point out that one of the main problems of choice in logistics is vehicle selection problem for multimodal transportation, which should rely on their compliance with certain criteria, and take into account not only possible risks and advantages (gains), but also more a wide range of indicators. In this regard, for an effec-tive problem-solving, a method for vehicle selection
\end{abstract}

\footnotetext{
${ }^{1}$ Doctor of Technical Sciences, Professor, Professor at Department of Software Engineering, Petro Mohyla Black Sea National University, Ukraine

${ }^{2}$ Candidate of Technical Sciences,

Associate Professor at Department of Software Engineering, Petro Mohyla Black Sea National University, Ukraine

(C) Igor Kovalenko, Alyona Shved
} 
problem-solving for multi-modal transportation of goods under multicriteria based on the BOCR model has been proposed. This approach allows to take into account a number of qualitative indicators of transportation that determine its optimality and efficiency. Improving the quality and reliability of the results of examinations can be achieved through the organization of the expert group work. Thus, the problem of synthesis of group decisions arises. The methodology for aggregating individual expert assessments, which allows to synthesize group decisions in the context of various forms of ignorance, under the influence of which expert assessments are formed has been proposed. The proposed technique allows to take into account the form of experts' judgments presentation (crisp, fuzzy, interval judgments) in group decision-making process. In this case, the expert independently chooses the form for presenting his judgments when constructing pairwise comparisons matrices. At the same time, the expert may refuse to evaluate any objects, or select preferred groups of objects (construct the so-called truncated matrices of pairwise comparisons). To aggregate expert assessments, it is proposed to use a mechanism for expert evidence in the framework of notation of evidence theory or the theory of plausible and paradoxical reasoning (with a significant level of conflict). This allows to increase the reliability and quality of the obtained expert evidence. Examples of practical implementation of the proposed technology are given by solving the problem of multi-criteria se-lection of vehicles for multimodal transportation of grain cargoes using the BOCR model. The obtained results allow to conduct a deeper analysis of factors affecting the organization of the multimodal transportation process, and are designed to help improve the quality and efficiency of the decision-making processes in logistics systems.

\section{Introduction}

Multimodal (combined) transport used different modes of transport for goods transportation in space and time, and occupy an important place in transport logistics. It should be noted that the results of such transportation largely depend on various types of uncertainty and risks. The main causes of which are the unevenness of material and traffic flows, using various types of vehicles, the conditions of transport corridors and nodes, features of transportation technologies, etc. This gives rise to a wide variety of tasks that could be solved by using decision support, forecasting, optimization 
methods in logistics systems and the construction on this basis the applied information technologies. The analysis of existing models and methods of decision making and optimization of logistics systems showed that they are directed either towards the choice of decisions regarding risks, or towards the solution of a problem regarding gains [2, p. 34-50]. The discussion of the issue of approaches to complex accounting of both gains and risks is insufficiently reflected in modern literature. During recent years, many works of both domestic and foreign researchers have been devoted to different problems of logistics industry, in particular, mathematical models and methods for solving various optimization and decision-making problems. So, the problem of logistics system optimization in business based on game theory models has been considered in [2, p. 91-103; 3; 9, p. 150-159] are devoted to the analysis of the criteria for various vehicles selection in multimodal transportation [11, p. 238-250] is considered a probabilistic approach for managing uncertainty in logistics operations. A fairly extensive classifier of mathematical methods and models in logistics is presented in $[12$, p. 9].

At the same time, it is necessary to point out the insufficiency of solution of choice problem under multicriteria environment, that taking into account not only the simultaneous consideration of risks and gains, but also a wider range of indicators. In this regard, to solve this problem, it seems more promising to use the BOCR model: $\mathrm{B}$ are Benefits, $\mathrm{O}$ are Opportunities, $\mathrm{C}$ are Costs, $\mathrm{R}$ are Risks, based on the analytic hierarchy process by T. Saaty (further-AHP) [13, p. 182].

The purpose of the work is to develop and define the basics of the technology for the synthesis of group decisions in vehicle selection problem for multimodal cargo transportation under multicriteriality and various types of ignorance, under the influence of which the expert data is formed.

\section{Using the BOCR model for multi-criteria decision-making}

Any solution has advantages and disadvantages that must be carefully analyzed when making a choice. Some of them reflect well-defined aspects of the problem, others are less clear and may occur with some probability. Favorable aspects of the decision, which are expected with a high probability, are called benefits, while unfavorable aspects are called costs. Doubtful aspects of a decision can also be positive and negative. The positive aspects are the opportunities that can be obtained, and the 
negative aspects are called the risks that may arise as a result of decisions made. Each of the four listed aspects of the BOCR model can be represented by a separate hierarchical structure and analyzed using the AHP technique (Figure 1).

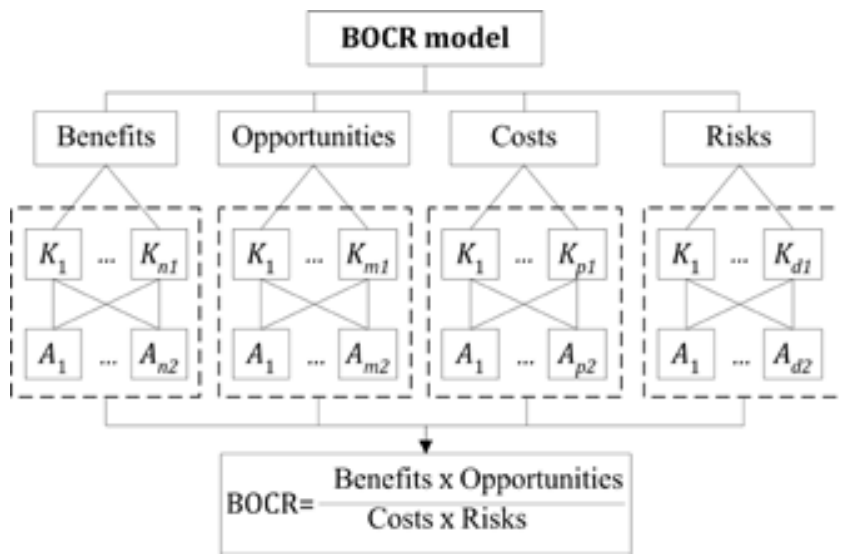

Figure 1. Structural representation of the BOCR model

The basics of AHP methodology are associated with the following procedures: for each aspect, the pairwise comparisons matrices $[B]$ are generated between for the criteria $[K]$ and for all alternatives $[A]$ according to each criterion using the appropriate scale of experts' measurement; the values of the eigenvector $(C)$ of this matrix are determined with their subsequent normalization and the final calculation of the weights of the priority vector is made. Next, the consistency check of the elements of matrix $[B]$ is performed based on counting the Consistency Ratio $(C R)$. The CR should not exceed $10 \%$.

Ultimately, for each of the considered alternatives, the BOCR coefficient is calculated as follows:

$$
\text { BOCR }=\frac{\text { Benefits } \times \text { Opportunities }}{\text { Cos } t s \times \text { Risks }} .
$$

By the magnitude of the BOCR coefficient, the final choice of the alternative is made or ranking of alternatives can be obtained. 


\section{Technology for synthesis of group decisions under imprecision}

Let a group of experts $\mathrm{E}=\left\{E_{j} \mid j=\overline{1, t}\right\}$, evaluating a set of alternatives $\mathrm{A}=\left\{A_{i} \mid i=\overline{1, m}\right\}$ by the pairwise comparison method, form a set of expert preferences profiles $\mathrm{P}=\left\{B_{j} \mid j=\overline{1, t}\right\}$. The profile formed by the expert $E_{j}$ reflects his preferences and presents his assessments in the form of a pairwise comparison matrix (PCM):

$$
B_{j}=\left(\begin{array}{cccccc}
1 & b_{12} & \ldots & b_{1 i} & \ldots & b_{1 m} \\
b_{21} & 1 & \ldots & b_{2 i} & \ldots & b_{2 m} \\
\ldots & \ldots & 1 & \ldots & \ldots & \ldots \\
b_{i 1} & b_{i 2} & \ldots & 1 & \ldots & b_{i m} \\
\ldots & \ldots & \ldots & \ldots & 1 & \ldots \\
b_{m 1} & b_{m 2} & \ldots & b_{m i} & \ldots & 1
\end{array}\right),
$$

where $b_{i j}=1 / b_{j i}, \forall i, j=\overline{1, m} ; b_{i j}$ are expert estimates of objects (alternatives, criteria) formed using the appropriate scale of experts' measurement.

Let us consider a situation when an expert group is divided into subgroups $E \subseteq\left\{G r_{1}\right\},\left\{G r_{2}\right\}, \ldots,\left\{G r_{p}\right\},\left(G r_{p} \subseteq \mathrm{E},\left\{G r_{p}\right\}=\left\{E_{1}, \ldots, E_{r}\right\}, t \geq r \geq 1\right)$ inside whose experts' assessments are presented in the framework of different scales of experts' measurements.

This approach allows to simulate the uncertainty associated with the process of obtaining expert information (expert assessments), by presenting imprecision associated with the form of presentation of expert assessments.

For example, there is a group of experts who prefer to express their judgments in fuzzy form; another group of experts prefers to express their judgments in crisp form; some experts decided not to evaluate all the alternatives given. The task is to synthesize a group solution allowing to take into account various forms of representing of experts' preferences.

In case when $b_{i j}$ is expressed by crisp experts' estimates the procedure for finding eigenvectors of matrix in form as shown in Eq. 2 can be implemented by geometric mean method [14, p. 18-19]. Checking the consistency of the elements of the matrix (2) is carried out by counting the Consistency Ratio $(C R)$ [14, p. 20]:

$$
\mathrm{CR}=\mathrm{CI} / \mathrm{RI} \text {, }
$$

where $m$ is a number of compared objects (order of matrix); $C I$ is a consistency index, $C I=\left(\lambda_{\max }-m\right) /(m-1) ; \lambda_{\max }$ is a largest eigenvector of a matrix 
of order $m, \lambda_{\max }=\left(\sum_{j=1}^{m_{1}} b_{j}\right) \cdot w_{1}+\left(\sum_{j=1}^{m_{2}} b_{j}\right) \cdot w_{2}+\ldots+\left(\sum_{j=1}^{m_{n}} b_{j}\right) \cdot w_{m} ; R I$ is a random index for a matrix of order $m$.

The calculated eigenvector of pairwise comparison matrix is acceptable if $C R \leq 0.10$.

In case when $b_{i j}$ is expressed by triangular fuzzy number (TFN) $b_{i j}=\left(b_{i j}^{1}, b_{i j}^{2}, b_{i j}^{3}\right),\left(b_{i j}^{1}<b_{i j}^{2}<b_{i j}^{3}\right), b_{j i}=\left[\frac{1}{b_{i j}^{3}}, \frac{1}{b_{i j}^{2}}, \frac{1}{b_{i j}^{1}}\right]$, or trapezoidal fuzzy number $b_{i j}=\left(b_{i j}^{1}, b_{i j}^{2}, b_{i j}^{3}, b_{i j}^{4}\right),\left(b_{i j}^{1}<b_{i j}^{2}<b_{i j}^{3}<b_{i j}^{4}\right), b_{j i}=\left[\frac{1}{b_{i j}^{4}}, \frac{1}{b_{i j}^{3}}, \frac{1}{b_{i j}^{2}}, \frac{1}{b_{i j}^{1}}\right]$, the fuzzy pairwise comparison matrix in form as shown in Eq. 2 has been formed. [6, p. 56-81] proposes a wide range of approached for finding eigenvectors of matrix (2), which allow processing fuzzy pairwise comparison matrices with the elements are repre-sented by trapezoidal and triangular fuzzy numbers.

$[4$, p. 1916; 8] propose the method for checking the consistency of the pairwise comparison matrix with triangular fuzzy elements:

$$
C C I=\frac{2}{(m-1)(m-2)} \sum_{i<j}\left(\log \left(\frac{b_{i j}^{1}+b_{i j}^{2}+b_{i j}^{3}}{3}\right)-\log \left(\frac{w_{i}^{1}+w_{i}^{2}+w_{i}^{2}}{w_{j}^{1}+w_{j}^{2}+w_{j}^{2}}\right)\right)^{2},
$$

where $b_{i j}=\left(b_{i j}^{1}, b_{i j}^{2}, b_{i j}^{3}\right) ; w_{j}=\left(w_{j}^{1}, w_{j}^{2}, w_{j}^{3}\right)$ is a local priority vector; $\mathrm{m}$ is an order of matrix.

If $C C I=0$, the matrix is considered absolutely consistent. [1;4, p. 1916] suggests threshold values for matrices of order $m=3 C C I=0.3147$, of order $m=4 C C I=0.3526$, of order $m>4 C C I=0.370$.

In case when $b_{i j}$ is represented by an interval number, then as a result of the pairwise comparisons procedure, an interval pairwise comparison matrix in form as shown in Eq. 2. will be obtained, where $b_{i j}=\left[b_{i j}^{1}, b_{i j}^{2}\right]$, $\left(b_{i j}^{1}<b_{i j}<b_{i j}^{2}<0\right), b_{j i}=\left[\frac{1}{b_{i j}^{2}}, \frac{1}{b_{i j}^{1}}\right], b_{i i}=b_{i i}^{1}=b_{i i}^{2}=1$.

Interval PCM is consistent if the next valid area is nonempty [20, p. 480]:

$$
S=\left\{w=\left(w_{1}, w_{2}, \ldots, w_{m}\right) \mid b_{i j}^{1} \leq w_{i} / w_{j} \leq b_{i j}^{2}, \sum_{i=1}^{m} w_{i}=1, w_{i}>0\right\} .
$$

Interval PCM is consistent if its elements satisfy the inequality [21, p. 256]:

$$
\max _{k}\left(b_{i k}^{1}, b_{k j}^{1}\right) " \min _{k}\left(b_{i k}^{2}, b_{k j}^{2}\right) \text { for } \forall(i, j, k)=\overline{1, m} \text {. }
$$


To obtain the values of the local priority vector from an interval PCM, currently widely used are: goal programming method (LGPPM) [22; p. 460], the lower and upper approximation method (LUAM) [19, p. 746], the twostage logarithmic goal programming method TSLGP [20, p. 477-481], etc.

The main disadvantage of the considered methods based on pairwise comparison technique is that they can be used for a small number of compared objects (elements). Analyzing perhaps the most well-known method for solving multicriteria decision-making problem - the analytic hierarchy process method, it can be pointed out the following disadvantages:

- it is quite difficult to achieve a high level of consistency with an increase in the number of compared elements $(n \geq 6)$;

- for large $\mathrm{n}$, it is necessary to construct a large number of PCMs;

- the classical AHP does not operate with uncertain experts' judgements (an expert is not allowed to answer "I don't know" or "I'm not sure" during the PCMs construction).

To overcome these limitations, it can be used the modern methods for managing uncertainty that have appeared recently. Such approaches include the methods of the Dempster-Shafer Theory (DST, evidence theory) and the Dezert-Smarandache Theory (DSmT, theory of plausible and paradoxical reasoning) [7, p. 15-18].

For example, the DST/AHP method is a modification of the analytic hierarchy process method proposed by T. Saaty, which is based on elements of evidence theory. The main difference between the DST/AHP method and the AHP method is that the expert, according to each of the criteria, selects subgroups from the set of alternatives, and for each subgroup, in a given relation scale, assigns degrees of its superiority to other alternatives. Moreover, the expert himself determines for which alternatives or groups of alternatives he can express his preferences.

Formally, the procedure for finding the group decision under different forms of uncertainty based on pairwise comparison method can be represented in the form of the following successive stages:

1. Construction of a hierarchical structure of analyzed problem with several levels: goals - criteria - alternatives. In the framework of this stage, the set of analyzed objects (alternatives) $\mathrm{A}=\left\{A_{i} \mid i=\overline{1, m}\right\}$ and set of criteria $\mathrm{K}=\left\{K_{l} \mid l=\overline{1, n}\right\}$ (for multicriteria task) are formed.

2. Objects evaluation, construction of pairwise comparison matrices. As a result, pairwise comparisons matrices for the criteria and for the alternatives with respect to all given criteria are formed. 
3. Calculation of priorities from pairwise comparison matrices, taking into ac-count the form of experts' judgments. As a result of this procedure the local priority vectors of all given alternatives for all criteria and the local priority vector of all criteria will be formed. The choice of method depends on the form of presentation of expert assessments: crisp, fuzzy, interval experts' judgments.

4. Checking the consistency of experts' judgments.

5. Calculation of quantitative indicator of the quality of each alternative using expression:

$$
U_{i}=\sum_{j=1}^{n} w_{j} r_{i j},
$$

where $U_{i}$ is quantitative indicator of the quality of $i$-th alternative; $w_{j}$ is a weight of $j$-th criterion; $r_{i j}$ is a weight of $i$-th alternative for the $j$-th criterion.

As a result of this procedure, the vector $W=\left\{W_{j} \mid j=\overline{1, t}\right\}$ will be formed, whose elements are the vectors of quantitative indicators of the quality of each alternative $W_{j}=\left\{U_{i}^{j} \mid i=\overline{1, m}\right\}$ obtained on the basis of expert $E_{j},(j=\overline{1, t})$, judgments.

6. Aggregation of expert assessments in order to construction the collective decision (collective ranking) is carried out on the basis of the mechanism of their combination $[17$, p. 6-9; 18, p. 3-68; 15, p. 31-45]. To aggregate crisp expert assessments, it is recommended to use one of the proportional conflict redistribution rules [18, p. 3-68]; to aggregate interval expert assessments, it is recommended to use one of the evidence theory combination rules $[15$, p. 31-45]. The aggregation procedure is carried out by combining the obtained values $W_{j}$ for all experts $\mathrm{E}=\left\{E_{j} \mid j=\overline{1, t}\right\}$. The result of this procedure is a vector of quantitative indicators of the quality of each alternative $W^{r e z}=\left\{U_{i}^{r e z} \mid i=\overline{1, m}\right\}$, reflecting the opinion of expert group.

\section{Modeling by proposed technology for synthesis of group decisions}

Let us consider an example of solving the vehicles selection problem in multi-modal transportation of bulk cargo (e.g. grain) using the BOCR model under multicriteriality, and uncertainty connected with form of expert preferences presentation (interval, fuzzy, crisp). To this end, let us consider the following notation:

1. Criteria for the "Benefits" aspect: $K_{1}$ - delivery time; $K_{2}$ - transportation costs; $K_{3}$ - shipment frequency; $K_{4}$ - transported cargo volume; 
2. Criteria for the "Cost" aspect: $K_{5}$ - financing of road infrastructures (upgrade and modernization); $K_{6}$ - investments in transportation vehicles (wagons, motor vehicles, railed vehicles, watercraft, aircraft, etc.); $K_{7}$ - investments in the production and technical base of transit corridors and nodes;

3. Criteria for the "Opportunities" aspect: $K_{8}$ - bandwidth; $K_{9}$ - the ability to deliver goods to any required place; $K_{10}$ - tariff rates for transportation; $K_{11}$ - weather conditions;

4. Criteria for the "Risks" aspect: $K_{12}$ - risk of failure to fulfill cargo safety obligations; $K_{13}$ - risk of failure to fulfill cargo delivery time obligations.

Let us consider next alternatives characterizing the modes of transportation of grain cargo: $A_{1}$ - "Truck-Truck"; $A_{2}$ - "Truck-Train"; $A_{3}$ - " TruckShip." Structurally, the problem is presented in Fig. 2.

Suppose that two experts are performed the examination. Let expert $E_{1}$ evaluates the significance of one object of examination (alternative) over the other with a triangular fuzzy number $b_{i j}=\left(l_{i j}, m_{i j}, u_{i j}\right)$ formed within the framework of a verbal scale expressing the degree of superiority of one element over another [10, p. 206], Table 1.

Table 1

Triangular Fuzzy Scale

\begin{tabular}{|l|c|c|}
\hline \multicolumn{1}{|c|}{ Verbal scale } & Triangular fuzzy scale, $\boldsymbol{b}_{\boldsymbol{i} \boldsymbol{j}}$ & Triangular fuzzy scale, $\boldsymbol{b}_{\boldsymbol{j} \boldsymbol{i}}$ \\
\hline Equal importance & $(1,1,1)$ & $(1,1,1)$ \\
\hline Some superiority & $(1 / 2,1,3 / 2)$ & $(2 / 3,1,2)$ \\
\hline Weak superiority & $(1,3 / 2,2)$ & $(1 / 2,2 / 3,1)$ \\
\hline Strong superiority & $(3 / 2,2,5 / 2)$ & $(2 / 5,1 / 2,2 / 3)$ \\
\hline Very strong superiority & $(2,5 / 2,3)$ & $(1 / 3,2 / 5,1 / 2)$ \\
\hline Absolute superiority & $(5 / 2,3,7 / 2)$ & $(2 / 7,1 / 3,2 / 5)$ \\
\hline
\end{tabular}

For vector of local priorities calculating the Chang method was used [5, p. 352; 6, p. 69-72]. The main ideas of the method are as follows:

1. Calculate the sum of the elements of each row and normalize the resulting value

$$
\tilde{S}_{i}=\sum_{j=1}^{m} b_{i j} \otimes\left[\sum_{i=1}^{m} \sum_{j=1}^{m} b_{i j}\right]^{-1} ;
$$




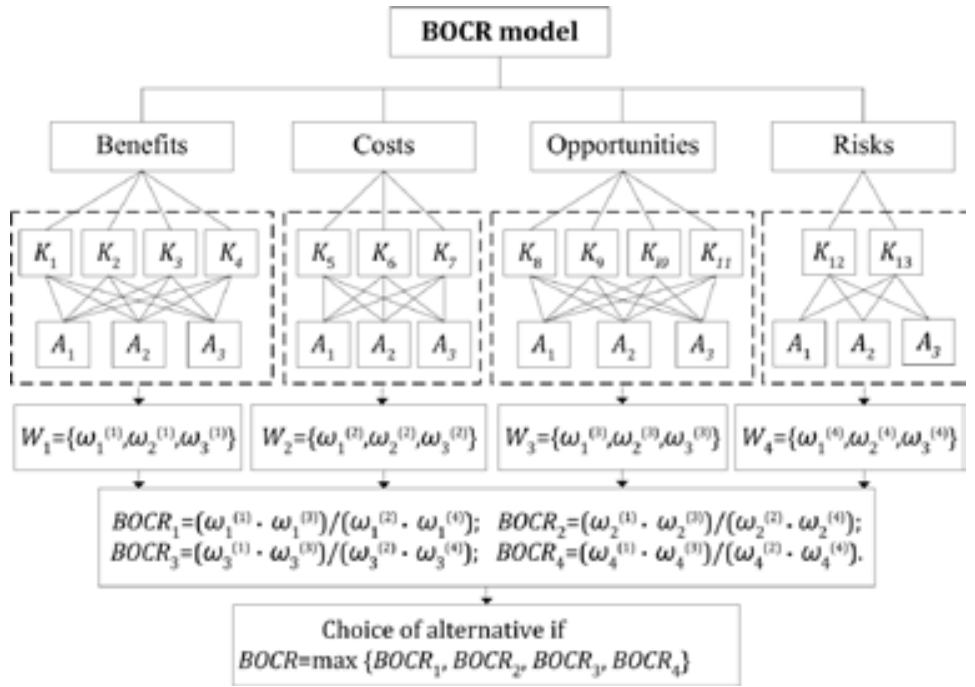

Figure 2. The structure of vehicles selection problem using the BOCR method

where:

$\sum_{j=1}^{m} b_{i j}=\left(\sum_{j=1}^{m} l_{i j} ; \sum_{j=1}^{m} m_{i j} ; \sum_{j=1}^{m} u_{i j}\right) ;\left[\sum_{i=1}^{m} \sum_{j=1}^{m} b_{i j}\right]^{-1}=\left(\frac{1}{\sum_{k=1}^{m} \sum_{j=1}^{m} u_{i j}} ; \frac{1}{\sum_{k=1}^{m} \sum_{j=1}^{m} m_{i j}} ; \frac{1}{\sum_{k=1}^{m} \sum_{j=1}^{m} l_{i j}}\right)$;

$b_{k} \otimes b_{p} \quad$ is $\quad-$ multiplication of triangular fuzzy numbers, $b_{k} \otimes b_{p}=\left(l_{k} \times l_{p}, m_{k} \times m_{p}, u_{k} \times u_{p}\right)$;.

2. Calculate the degree of probability of $\tilde{S}_{i} \geq \tilde{S}_{j}$ as follows:

$$
V\left(\tilde{S}_{i} \geq \tilde{S}_{j}\right)= \begin{cases}1, & m_{j} \geq m_{i} ; \\ 0, & l_{i} \geq u_{j} ; \\ \frac{u_{i}-l_{j}}{\left(u_{i}-m_{i}\right)+\left(m_{j}-l_{j}\right)}, & \text { otherwise. }\end{cases}
$$

3. Calculate the degree of probability of $\tilde{S}_{i}$ relative to other $(n-1)$ fuzzy ratings

$$
V\left(\tilde{S}_{i} \geq \tilde{S}_{j} \mid j=\overline{1, m}, i \neq j\right)=\min _{j=1, m, i \neq j} V\left(\tilde{S}_{i} \geq \tilde{S}_{j}\right), \quad i=\overline{1, m}
$$


4. Calculate the priority vector values:

$$
\omega_{i}=\frac{V\left(\tilde{S}_{i} \geq \tilde{S}_{j} \mid j=\overline{1, m}, i \neq j\right)}{\sum_{k=1}^{m} V\left(\tilde{S}_{i} \geq \tilde{S}_{j} \mid j=\overline{1, m}, i \neq j\right)}, \quad i=\overline{1, m} .
$$

The results of pairwise comparisons for all four aspects based on fuzzy expert judgments are given in Tables 2 to 9 .

Table 2

\section{Results of Pairwise Comparisons of a Set of Alternatives for the "Benefits" Aspect}

\begin{tabular}{|c|c|c|c|c|c|c|}
\hline & \multicolumn{3}{|c|}{ Criterion $K_{1}$} & \multicolumn{3}{|c|}{ Criterion $K_{2}$} \\
\hline & $A_{1}$ & $A_{2}$ & $A_{3}$ & $A_{1}$ & $A_{2}$ & $A_{3}$ \\
\hline$A_{1}$ & $(1,1,1)$ & $(1,3 / 2,2)$ & $(2,5 / 2,3)$ & $(1,1,1)$ & $(1 / 2,2 / 3,1)$ & $(2 / 5,1 / 2,2 / 3)$ \\
\hline$A_{2}$ & $(1 / 2,2 / 3,1)$ & $(1,1,1)$ & $(3 / 2,2,5 / 2)$ & $(1,3 / 2,2)$ & $(1,1,1)$ & $(1 / 2,1,3 / 2)$ \\
\hline \multirow[t]{3}{*}{$A_{3}$} & $(1 / 3,2 / 5,1 / 2)$ & $(2 / 5,1 / 2,2 / 3)$ & $(1,1,1)$ & $(3 / 2,2,5 / 2)$ & $(2 / 3,1,2)$ & $(1,1,1)$ \\
\hline & \multicolumn{3}{|c|}{ Criterion $K_{3}$} & \multicolumn{3}{|c|}{ Criterion $K_{4}$} \\
\hline & $A_{1}$ & $A_{2}$ & $A_{3}$ & $A_{1}$ & $A_{2}$ & $A_{3}$ \\
\hline$A_{1}$ & $(1,1,1)$ & $(1 / 2,1,3 / 2)$ & $(3 / 2,2,5 / 2)$ & $(1,1,1)$ & $(1 / 2,1,3 / 2)$ & $(2 / 7,1 / 3,2 / 5)$ \\
\hline$A_{2}$ & $(2 / 3,1,2)$ & $(1,1,1)$ & $(1 / 2,1,3 / 2)$ & $(2,5 / 2,3)$ & $(1,1,1)$ & $(2 / 3,1,2)$ \\
\hline$A_{3}$ & $(2 / 5,1 / 2,2 / 3)$ & $(1 / 3,2 / 5,1 / 2)$ & $(1,1,1)$ & $(5 / 2,3,7 / 2)$ & $(1 / 2,1,3 / 2)$ & $(1,1,1)$ \\
\hline
\end{tabular}

Table 3

Results of Pairwise Comparisons of a Set of Criteria for the "Benefits" Aspect

\begin{tabular}{|c|c|c|c|c|}
\hline & $K_{1}$ & $K_{2}$ & $K_{3}$ & $K_{4}$ \\
\hline$K_{1}$ & $(1,1,1)$ & $(2 / 5,1 / 2,2 / 3)$ & $(1 / 2,1,3 / 2)$ & $(1,3 / 2,2)$ \\
\hline$K_{2}$ & $(3 / 2,2,5 / 2)$ & $(1,1,1)$ & $(2,5 / 2,3)$ & $(2,5 / 2,3)$ \\
\hline$K_{3}$ & $(2 / 3,1,2)$ & $(1 / 3,2 / 5,1 / 2)$ & $(1,1,1)$ & $(1,3 / 2,2)$ \\
\hline$K_{4}$ & $(1 / 2,2 / 3,1)$ & $(1 / 3,2 / 5,1 / 2)$ & $(1 / 2,2 / 3,1)$ & $(1,1,1)$ \\
\hline
\end{tabular}

The local priority vectors of the alternatives:

- for the criterion $K_{1}: r_{1}^{1}=(0.61 ; 0.39 ; 0)$;

- for the criterion $K_{2}: r_{2}^{1}=(0.16 ; 0.44 ; 0.40)$;

- for the criterion $K_{3}: r_{3}^{1}=(0.51 ; 0.39 ; 0.10)$;

- for the criterion $K_{4}: r_{4}^{1}=(0.07 ; 0.44 ; 0.49)$.

The local priority vector of the criteria: $w_{1}^{1}=(0.17 ; 0.64 ; 0.20 ; 0.00)$. 
Let us calculate a quantitative indicator of the quality of each alternative for the "Benefits" aspect: $U_{1}=0.31 ; U_{2}=0.42 ; U_{3}=0.27$.

Table 4

Results of Pairwise Comparisons of a Set of Alternatives

for the "Costs" Aspect

\begin{tabular}{|c|c|c|c|c|c|c|}
\hline & \multicolumn{3}{|c|}{ Criterion $K_{5}$} & \multicolumn{3}{|c|}{ Criterion $K_{6}$} \\
\hline & $A_{1}$ & $A_{2}$ & $A_{3}$ & $A_{1}$ & $A_{2}$ & $A_{3}$ \\
\hline$A_{1}$ & $(1,1,1)$ & $(2,5 / 2,3)$ & $(3 / 2,2,5 / 2)$ & $(1,1,1)$ & $(1 / 2,2 / 3,1)$ & $(2 / 3,1,2)$ \\
\hline$A_{2}$ & $(1 / 3,2 / 5,1 / 2)$ & $(1,1,1)$ & $(1 / 2,1,3 / 2)$ & $(1,3 / 2,2)$ & $(1,1,1)$ & $(1,3 / 2,2)$ \\
\hline \multirow[t]{3}{*}{$A_{3}$} & $(2 / 5,1 / 2,2 / 3)$ & $(2 / 3,1,2)$ & $(1,1,1)$ & $(1 / 2,1,3 / 2)$ & $(1 / 2,2 / 3,1)$ & $(1,1,1)$ \\
\hline & \multicolumn{3}{|c|}{ Criterion $K_{7}$} & & & \\
\hline & $A_{1}$ & $A_{2}$ & $A_{3}$ & & & \\
\hline$A_{1}$ & $(1,1,1)$ & $(1 / 2,2 / 3,1)$ & $(1 / 3,2 / 5,1 / 2)$ & & & \\
\hline$A_{2}$ & $(1,3 / 2,2)$ & $(1,1,1)$ & $(1 / 2,2 / 3,1)$ & & & \\
\hline$A_{3}$ & $(2,5 / 2,3)$ & $(1,3 / 2,2)$ & $(1,1,1)$ & & & \\
\hline
\end{tabular}

Table 5

Results of Pairwise Comparisons of a Set of Criteria for the "Costs" Aspect

\begin{tabular}{|c|c|c|c|}
\hline & $K_{5}$ & $K_{6}$ & $K_{7}$ \\
\hline$K_{5}$ & $(1,1,1)$ & $(1,3 / 2,2)$ & $(3 / 2,2,5 / 2)$ \\
\hline$K_{6}$ & $(1 / 2,2 / 3,1)$ & $(1,1,1)$ & $(1,3 / 2,2)$ \\
\hline$K_{7}$ & $(2 / 5,1 / 2,2 / 3)$ & $(1 / 2,2 / 3,1)$ & $(1,1,1)$ \\
\hline
\end{tabular}

The local priority vector of the alternatives:

- for the criterion $K_{5}: r_{5}^{1}=(0.77 ; 0.04 ; 0.19)$;

- for the criterion $K_{6}: r_{6}^{1}=(0.30 ; 0.43 ; 0.27)$;

- for the criterion $K_{7}: r_{7}^{1}=(0.00 ; 0.32 ; 0.68)$.

The local priority vectors of the criteria $w_{2}^{1}=(0.56 ; 0.34 ; 0.10)$.

Let us calculate a quantitative indicator of the quality of each alternative for the "Costs" aspect: $U_{1}=0.53 ; U_{2}=0.20 ; U_{3}=0.27$. 


\section{Results of Pairwise Comparisons of a Set of Alternatives for the "Opportunities" Aspect}

\begin{tabular}{|c|c|c|c|c|c|c|}
\hline & \multicolumn{3}{|c|}{ Criterion $K_{8}$} & \multicolumn{3}{c|}{ Criterion $K_{9}$} \\
\hline & $A_{1}$ & $A_{2}$ & $A_{3}$ & $A_{1}$ & $A_{2}$ & $A_{3}$ \\
\hline$A_{1}$ & $(1,1,1)$ & $(1 / 2,1,3 / 2)$ & $(1,3 / 2,2)$ & $(1,1,1)$ & $(2,5 / 2,3)$ & $(1,3 / 2,2)$ \\
\hline$A_{2}$ & $(2 / 3,1,2)$ & $(1,1,1)$ & $(3 / 2,2,5 / 2)$ & $(1 / 3,2 / 5,1 / 2)$ & $(1,1,1)$ & $(1 / 2,1,3 / 2)$ \\
\hline$A_{3}$ & $(1 / 2,2 / 3,1)$ & $(2 / 5,1 / 2,2 / 3)$ & $(1,1,1)$ & $(1 / 2,2 / 3,1)$ & $(2 / 3,1,2)$ & $(1,1,1)$ \\
\hline & \multicolumn{3}{|c|}{ Criterion $K_{10}$} & \multicolumn{3}{c|}{ Criterion $K_{11}$} \\
\hline & $A_{1}$ & $A_{2}$ & $A_{3}$ & $A_{1}$ & $A_{2}$ & $A_{3}$ \\
\hline$A_{1}$ & $(1,1,1)$ & $(1 / 2,2 / 3,1)$ & $(1 / 3,2 / 5,1 / 2)$ & $(1,1,1)$ & $(2 / 5,1 / 2,2 / 3)$ & $(1 / 2,2 / 3,1)$ \\
\hline$A_{2}$ & $(1,3 / 2,2)$ & $(1,1,1)$ & $(2 / 5,1 / 2,2 / 3)$ & $(3 / 2,2,5 / 2)$ & $(1,1,1)$ & $(1,3 / 2,2)$ \\
\hline$A_{3}$ & $(2,5 / 2,3)$ & $(3 / 2,2,5 / 2)$ & $(1,1,1)$ & $(1,3 / 2,2)$ & $(1 / 2,2 / 3,1)$ & $(1,1,1)$ \\
\hline
\end{tabular}

Table 7

\section{Results of Pairwise Comparisons of a Set of Criteria for the "Opportunities" Aspect}

\begin{tabular}{|c|c|c|c|c|}
\hline & $K_{8}$ & $K_{9}$ & $K_{10}$ & $K_{11}$ \\
\hline$K_{8}$ & $(1,1,1)$ & $(2 / 3,1,2)$ & $(2 / 3,1,2)$ & $(1 / 2,1,3 / 2)$ \\
\hline$K_{9}$ & $(1 / 2,1,3 / 2)$ & $(1,1,1)$ & $(1 / 2,1,3 / 2)$ & $(1,3 / 2,2)$ \\
\hline$K_{10}$ & $(1 / 2,1,3 / 2)$ & $(2 / 3,1,2)$ & $(1,1,1)$ & $(1,3 / 2,2)$ \\
\hline$K_{11}$ & $(2 / 3,1,2)$ & $(1 / 2,2 / 3,1)$ & $(1 / 2,2 / 3,1)$ & $(1,1,1)$ \\
\hline
\end{tabular}

The local priority vectors of the alternatives:

- for the criterion $K_{8}: r_{8}^{1}=(0.39 ; 0.45 ; 0.16)$;

- for the criterion $K_{9}: r_{9}^{1}=(0.60 ; 0.12 ; 0.27)$;

- for the criterion $K_{10}: r_{10}^{1}=(0.00 ; 0.18 ; 0.82)$;

- for the criterion $K_{11}: r_{11}^{1}=(0.10 ; 0.56 ; 0.34)$.

The local priority vector of the criteria $w_{3}^{1}=(0.25 ; 0.27 ; 0.27 ; 0.22)$.

Let us calculate a quantitative indicator of the quality of each alternative for the "Opportunities" aspect: $U_{1}=0.28 ; U_{2}=0.31 ; U_{3}=0.41$. 
Table 8

Results of Pairwise Comparisons of a Set of Alternatives

for the "Risks" Aspect

\begin{tabular}{|c|c|c|c|c|c|c|}
\hline & \multicolumn{3}{|c|}{ Criterion $K_{12}$} & \multicolumn{3}{c|}{ Criterion $K_{13}$} \\
\hline & $A_{1}$ & $A_{2}$ & $A_{3}$ & $A_{1}$ & $A_{2}$ & $A_{3}$ \\
\hline$A_{1}$ & $(1,1,1)$ & $(3 / 2,2,5 / 2)$ & $(1,3 / 2,2)$ & $(1,1,1)$ & $(1,3 / 2,2)$ & $(2,5 / 2,3)$ \\
\hline$A_{2}$ & $(2 / 5,1 / 2,2 / 3)$ & $(1,1,1)$ & $(2 / 3,1,2)$ & $(1 / 2,2 / 3,1)$ & $(1,1,1)$ & $(1 / 2,1,3 / 2)$ \\
\hline$A_{3}$ & $(1 / 2,2 / 3,1)$ & $(1 / 2,1,3 / 2)$ & $(1,1,1)$ & $(1 / 3,2 / 5,1 / 2)$ & $(2 / 3,1,2)$ & $(1,1,1)$ \\
\hline
\end{tabular}

Table 9

\section{Results of Pairwise Comparisons of a Set of Criteria} for the "Risks" Aspect

\begin{tabular}{|c|c|c|}
\hline & $K_{12}$ & $K_{13}$ \\
\hline$K_{12}$ & $(1,1,1)$ & $(2 / 3,1,2)$ \\
\hline$K_{13}$ & $(1 / 2,1,3 / 2)$ & $(1,1,1)$ \\
\hline
\end{tabular}

The local priority vectors of the alternatives:

- for the criterion $K_{12}: r_{12}^{1}=(0.50 ; 0.25 ; 0.25)$;

- for the criterion $K_{13}: r_{13}^{1}=(0.59 ; 0.21 ; 0.20)$.

The local priority vector of the criteria $w_{4}^{1}=(0.50 ; 0.50)$.

Let us calculate a quantitative indicator of the quality of each alternative for the "Risks" aspect: $U_{1}=0.55 ; U_{2}=0.23 ; U_{3}=0.22$.

As a result, form the priority vectors obtained on the basis of expert $E_{1}$ judg-ments:

Benefits: $W_{1}^{1}=(0.31 ; 0.42 ; 0.27) . \quad$ Costs: $W_{2}^{1}=(0.53 ; 0.20 ; 0.27)$.

Opportunities: $W_{3}^{1}=(0.28 ; 0.31 ; 0.41)$. Risks: $W_{4}^{1}=(0.55 ; 0.23 ; 0.22)$.

Let expert $E_{2}$ evaluates the significance of one object of examination (alternative) over the other in crisp form using the nine-point comparison scale: 1 - equal importance; 3 - moderate superiority; 5 - significant superiority; 7 - clear superiority; 9 - absolute domination; the values 2, 4, 6, 8 correspond to intermediate gradations $[14$, p. 53].

The geometric mean method was used for calculating local priorities: 


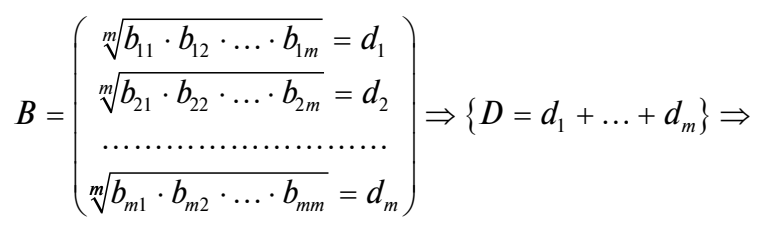

$$
\begin{aligned}
& \Rightarrow\left\{\frac{d_{1}}{D}=w_{1}, \ldots, \frac{d_{m}}{D}=w_{m}\right\} \Rightarrow\left(w_{1}, \ldots w_{m}\right) .
\end{aligned}
$$

The results of pairwise comparisons for all four aspects base on crisp experts' judgments are given in Tables 10 to 17 .

Table 10

\section{Results of Pairwise Comparisons of a Set of Alternatives for the "Benefits" Aspect}

\begin{tabular}{|c|c|c|c|c|c|c|}
\hline & \multicolumn{3}{|c|}{ Criterion $K_{1}$} & \multicolumn{3}{c|}{ Criterion $K_{2}$} \\
\hline & $A_{1}$ & $A_{2}$ & $A_{3}$ & $A_{1}$ & $A_{2}$ & $A_{3}$ \\
\hline$A_{1}$ & 1 & 3 & 5 & 1 & $1 / 3$ & $1 / 4$ \\
\hline$A_{2}$ & $1 / 3$ & 1 & 4 & 3 & 1 & 2 \\
\hline$A_{3}$ & $1 / 5$ & $1 / 4$ & 1 & 4 & $1 / 2$ & 1 \\
\hline & \multicolumn{3}{|c|}{ Criterion $K_{3}$} & \multicolumn{3}{c|}{ Criterion $K_{4}$} \\
\hline & $A_{1}$ & $A_{2}$ & $A_{3}$ & $A_{1}$ & $A_{2}$ & $A_{3}$ \\
\hline$A_{1}$ & 1 & 2 & 4 & 1 & 2 & $1 / 7$ \\
\hline$A_{2}$ & $1 / 2$ & 1 & 2 & 5 & 1 & $1 / 2$ \\
\hline$A_{3}$ & $1 / 4$ & $1 / 5$ & 1 & 7 & 2 & 1 \\
\hline
\end{tabular}

Results of Pairwise Comparisons of a Set of Criteria for the "Benefits" Aspect

\begin{tabular}{|c|c|c|c|c|}
\hline & $K_{1}$ & $K_{2}$ & $K_{3}$ & $K_{4}$ \\
\hline$K_{1}$ & 1 & $1 / 4$ & 2 & 3 \\
\hline$K_{2}$ & 4 & 1 & 5 & 5 \\
\hline$K_{3}$ & $1 / 2$ & $1 / 5$ & 1 & 3 \\
\hline$K_{4}$ & $1 / 3$ & $1 / 5$ & $1 / 3$ & 1 \\
\hline
\end{tabular}

The local priority vectors of the alternatives:

- for the criterion $K_{1}: r_{1}^{2}=(0.63 ; 0.28 ; 0.09)$;

- for the criterion $K_{2}: r_{2}^{2}=(0.12 ; 0.52 ; 0.36)$; 
- for the criterion $K_{3}: r_{3}^{2}=(0.57 ; 0.29 ; 0.14)$;

- for the criterion $K_{4}: r_{4}^{2}=(0.08 ; 0.33 ; 0.59)$.

The local priority vector of the criteria $w_{1}^{2}=(0.21 ; 0.59 ; 0.14 ; 0.07)$.

Let us calculate a quantitative indicator of the quality of each alternative for the "Benefits" aspect: $U_{1}=0.28 ; U_{2}=0.42 ; U_{3}=0.30$.

Table 12

\section{Results of Pairwise Comparisons of a Set of Alternatives}

for the "Costs" Aspect

\begin{tabular}{|c|c|c|c|c|c|c|}
\hline & \multicolumn{3}{|c|}{ Criterion $K_{5}$} & \multicolumn{3}{c|}{ Criterion $K_{6}$} \\
\hline & $A_{1}$ & $A_{2}$ & $A_{3}$ & $A_{1}$ & $A_{2}$ & $A_{3}$ \\
\hline$A_{1}$ & 1 & 5 & 4 & 1 & $1 / 3$ & $1 / 2$ \\
\hline$A_{2}$ & $1 / 5$ & 1 & 2 & 3 & 1 & 3 \\
\hline$A_{3}$ & $1 / 4$ & $1 / 2$ & 1 & 2 & $1 / 3$ & 1 \\
\hline \multicolumn{3}{|c|}{ Criterion $K_{7}$} & \multicolumn{3}{c}{} \\
\hline & $A_{1}$ & $A_{2}$ & $A_{3}$ & & \\
\hline$A_{1}$ & 1 & $1 / 3$ & $1 / 5$ & & \\
\hline$A_{2}$ & 3 & 1 & $1 / 3$ & & & \\
\hline$A_{3}$ & 5 & 3 & 1 & & & \\
\hline
\end{tabular}

Table 13

Results of Pairwise Comparisons of a Set of Criteria for the "Costs" Aspect

\begin{tabular}{|c|c|c|c|}
\hline & $K_{5}$ & $K_{6}$ & $K_{7}$ \\
\hline$K_{5}$ & 1 & 3 & 4 \\
\hline$K_{6}$ & $1 / 3$ & 1 & 3 \\
\hline$K_{7}$ & $1 / 4$ & $1 / 3$ & 1 \\
\hline
\end{tabular}

The local priority vectors of the alternatives:

- for the criterion $K_{5}: r_{5}^{2}=(0.69 ; 0.19 ; 0.13)$;

- for the criterion $K_{6}: r_{6}^{2}=(0.16 ; 0.59 ; 0.25)$;

- for the criterion $K_{7}: r_{7}^{2}=(0.10 ; 0.26 ; 0.64)$.

The local priority vector of the criteria $w_{2}^{2}=(0.61 ; 0.27 ; 0.12)$.

Let us calculate a quantitative indicator of the quality of each alternative for the "Costs": $U_{1}=0.48 ; U_{2}=0.30 ; U_{3}=0.22$. 
Table 14

Results of Pairwise Comparisons of a Set of Alternatives for the "Opportunities" Aspect

\begin{tabular}{|c|c|c|c|c|c|c|}
\hline & \multicolumn{3}{|c|}{ Criterion $K_{8}$} & \multicolumn{3}{|c|}{ Criterion $K_{9}$} \\
\hline & $A_{1}$ & $A_{2}$ & $A_{3}$ & $A_{1}$ & $A_{2}$ & $A_{3}$ \\
\hline$A_{1}$ & 1 & 2 & 3 & 1 & 5 & 3 \\
\hline$A_{2}$ & $1 / 2$ & 1 & 4 & $1 / 5$ & 1 & 2 \\
\hline \multirow[t]{3}{*}{$A_{3}$} & $1 / 3$ & $1 / 4$ & 1 & $1 / 3$ & $1 / 2$ & 1 \\
\hline & \multicolumn{3}{|c|}{ Criterion $K_{10}$} & \multicolumn{3}{|c|}{ Criterion $K_{11}$} \\
\hline & $A_{1}$ & $A_{2}$ & $A_{3}$ & $A_{1}$ & $A_{2}$ & $A_{3}$ \\
\hline$A_{1}$ & 1 & $1 / 3$ & $1 / 5$ & 1 & $1 / 4$ & $1 / 3$ \\
\hline$A_{2}$ & 3 & 1 & $1 / 4$ & 4 & 1 & 3 \\
\hline$A_{3}$ & 5 & 4 & 1 & 3 & $1 / 3$ & 1 \\
\hline
\end{tabular}

Table 15

\section{Results of Pairwise Comparisons of a Set of Criteria for the "Opportunities" Aspect}

\begin{tabular}{|c|c|c|c|c|}
\hline & $K_{8}$ & $K_{9}$ & $K_{10}$ & $K_{11}$ \\
\hline$K_{8}$ & 1 & $1 / 2$ & $1 / 2$ & 2 \\
\hline$K_{9}$ & 2 & 1 & 2 & 3 \\
\hline$K_{10}$ & 2 & $1 / 2$ & 1 & 3 \\
\hline$K_{11}$ & $1 / 2$ & $1 / 3$ & $1 / 3$ & 1 \\
\hline
\end{tabular}

The local priority vectors of the alternatives:

- for the criterion $K_{8}: r_{8}^{2}=(0.52 ; 0.36 ; 0.12)$;

- for the criterion $K_{9}: r_{9}^{2}=(0.66 ; 0.20 ; 0.14)$;

- for the criterion $K_{10}$ :

- for the criterion $K_{11}: r_{11}^{2}=(0.12 ; 0.61 ; 0.27)$.

The local priority vector of the criteria $w_{3}^{2}=(0.19 ; 0.41 ; 0.29 ; 0.11)$.

Let us calculate a quantitative indicator of the quality of each alternative for the "Opportunities" aspect: $U_{1}=0.41 ; U_{2}=0.28 ; U_{3}=0.31$. 
Table 16

Results of Pairwise Comparisons of a Set of Alternatives for the "Risks" Aspect

\begin{tabular}{|c|c|c|c|c|c|c|}
\hline & \multicolumn{3}{|c|}{ Criterion $K_{12}$} & \multicolumn{3}{c|}{ Criterion $K_{13}$} \\
\hline & $A_{1}$ & $A_{2}$ & $A_{3}$ & $A_{1}$ & $A_{2}$ & $A_{3}$ \\
\hline$A_{1}$ & 1 & 4 & 3 & 1 & 3 & 5 \\
\hline$A_{2}$ & $1 / 4$ & 1 & $1 / 2$ & $1 / 3$ & 1 & 2 \\
\hline$A_{3}$ & $1 / 3$ & 2 & 1 & $1 / 5$ & $1 / 2$ & 1 \\
\hline
\end{tabular}

Table 17

\section{Results of Pairwise Comparisons of a Set of Criteria} for the "Risks" Aspect

\begin{tabular}{|c|c|c|}
\hline & $K_{12}$ & $K_{13}$ \\
\hline$K_{12}$ & 1 & $1 / 2$ \\
\hline$K_{13}$ & 2 & 1 \\
\hline
\end{tabular}

The local priority vectors of the alternatives:

- for the criterion $K_{12}: r_{12}^{2}=(0.63 ; 0.14 ; 0.24)$;

- for the criterion $K_{13}: r_{13}^{2}=(0.65 ; 0.23 ; 0.12)$.

The local priority vector of the criteria: $w_{4}^{2}=(0.33 ; 0.67)$.

Let us calculate a quantitative indicator of the quality of each alternative for the "Risks" aspect: $U_{1}=0.64 ; U_{2}=0.20 ; U_{3}=0.16$.

As a result, form the priority vectors obtained on the basis of expert $E_{2}$ judg-ments:

Benefits: $W_{1}^{2}=(0.28 ; 0.42 ; 0.30) . \quad$ Costs: $W_{2}^{2}=(0.48 ; 0.30 ; 0.22)$.

Opportunities: $W_{3}^{2}=(0.41 ; 0.28 ; 0.31)$. Risks: $W_{4}^{2}=(0.64 ; 0.20 ; 0.16)$.

For synthesis of group decisions use the operation of combining experts' judg-ments (evidence):

"Benefits" aspect:

Expert 1: $m_{1}\left(A_{1}\right)=0.31 ; m_{1}\left(A_{2}\right)=0.42 ; m_{1}\left(A_{3}\right)=0.27$.

Expert 2: $m_{2}\left(A_{1}\right)=0.28 ; m_{2}\left(A_{2}\right)=0.42 ; m_{2}\left(A_{3}\right)=0.30$.

"Costs" aspect:

Expert 1: $m_{1}\left(A_{1}\right)=0.53 ; m_{1}\left(A_{2}\right)=0.20 ; m_{1}\left(A_{3}\right)=0.27$.

Expert 2: $m_{2}\left(A_{1}\right)=0.48 ; m_{2}\left(A_{2}\right)=0.30 ; m_{2}\left(A_{3}\right)=0.22$. 
"Opportunities" aspect:

Expert 1: $m_{1}\left(A_{1}\right)=0.28 ; m_{1}\left(A_{2}\right)=0.31 ; m_{1}\left(A_{3}\right)=0.41$.

Expert 2: $m_{2}\left(A_{1}\right)=0.41 ; m_{2}\left(A_{2}\right)=0.28 ; m_{2}\left(A_{3}\right)=0.31$.

"Risks" aspect:

Expert 1: $m_{1}\left(A_{1}\right)=0.55 ; m_{1}\left(A_{2}\right)=0.23 ; m_{1}\left(A_{3}\right)=0.22$.

Expert 2: $m_{2}\left(A_{1}\right)=0.64 ; m_{2}\left(A_{2}\right)=0.20 ; m_{2}\left(A_{3}\right)=0.16$.

The level of conflict is calculated as follows $[17$, p. 6]

$$
k_{12}=\sum_{j=1}^{3} m_{1}\left(A_{j}\right) \sum_{i=1, i \neq j}^{3} m_{2}\left(A_{i}\right) .
$$

Level of conflict for example was:

"Benefits" aspect: $\quad k_{12}=0.66 . \quad$ "Costs" aspect: $k_{12}=0.63$.

"Opportunities" aspect: $k_{12}=0.67$. "Risks" aspect: $k_{12}=0.57$.

Taking into account a rather high level of conflict, the PCR5 rule of combination was used to aggregate experts' judgments. This technique allows to redistribute conflicting basic belief assignments to the subsets involved in local conflicts [18, p. 36]. Let's $m_{1}(\cdot)$ and $m_{2}(\cdot)$ be two independent basic belief assignment ( $b b a$ 's), then the PCR5 rule of combination for two sources of evidence is defined as follows:

$$
m_{P C R 5}(C)=m_{12}(C) \sum_{\substack{Y \in G^{A} A\{X\} \\ X \cap Y=\varnothing}}\left[\frac{m_{1}(X)^{2} \cdot m_{2}(Y)}{m_{1}(X)+m_{1}(Y)}+\frac{m_{2}(X)^{2} \cdot m_{1}(Y)}{m_{2}(X)+m_{1}(Y)}\right],
$$

where $m_{12}(C)$ is combined basic belief assignment for a subset $C=X \cap Y$, calculated based on combination rules reflecting the conjunctive consensus; $G^{\mathrm{A}}=2^{\mathrm{A}}$ in DST framework, or $G^{\mathrm{A}}=D^{\mathrm{A}}$ in DSmT framework.

The power set $2 \mathrm{~A}$ is the set of all possible combinations of elements built from elements of A with $\cup[16 ; 17$, p. 5]. The hyper-power set (Dedekind's lattice) $D^{\mathrm{A}}$ is defined as the set of all possible combinations of elements built from elements of A with $\cap$ and $\cup[17$, p. 13-14].

The resulting combined belief probability assignments in accordance with PCR5 rule:

"Benefits" aspect:

$m_{12}\left(A_{1}\right)=0.28 ; m_{12}\left(A_{2}\right)=0.46 ; m_{12}\left(A_{3}\right)=0.26$.

"Costs" aspect:

$m_{12}\left(A_{1}\right)=0.59 ; m_{12}\left(A_{2}\right)=0.21 ; m_{12}\left(A_{3}\right)=0.20$. 
"Opportunities" aspect:

$m_{12}\left(A_{1}\right)=0.35 ; m_{12}\left(A_{2}\right)=0.28 ; m_{12}\left(A_{3}\right)=0.37$.

"Risks" aspect:

$m_{12}\left(A_{1}\right)=0.71 ; m_{12}\left(A_{2}\right)=0.16 ; m_{12}\left(A_{3}\right)=0.13$.

Calculated BOCR values shown in Table 18 .

Table 18

BOCR Values

\begin{tabular}{|l|c|c|c|c|}
\hline \multicolumn{1}{|c|}{ Alternatives } & $\boldsymbol{A}_{1}$ & $\boldsymbol{A}_{2}$ & $\boldsymbol{A}_{3}$ & Ranking \\
\hline Benefits & 0.28 & 0.46 & 0.26 & $A_{2} \succ A_{1} \succ A_{3}$ \\
\hline Costs & 0.59 & 0.21 & 0.20 & $A_{1} \succ A_{2} \succ A_{3}$ \\
\hline Benefits / Costs & 0.47 & 2.19 & 1.30 & $A_{2} \succ A_{3} \succ A_{1}$ \\
\hline Opportunities & 0.35 & 0.28 & 0.37 & $A_{3} \succ A_{1} \succ A_{2}$ \\
\hline Risks & 0.71 & 0.16 & 0.13 & $A_{1} \succ A_{2} \succ A_{3}$ \\
\hline Opportunities / Risks & 0.49 & 1.75 & 2.85 & $A_{3} \succ A_{2} \succ A_{1}$ \\
\hline Benefits /( Costs $\times$ Risks) & 0.67 & 13.69 & 10.00 & $A_{2} \succ A_{3} \succ A_{1}$ \\
\hline BOCR & 0.23 & 3.83 & 3.70 & $A_{2} \succ A_{3} \succ A_{1}$ \\
\hline
\end{tabular}

From the results listed in Table 18 it can be seen that, taking into account the obtained values of the considered transportation aspects for this example, $A_{2}$ is the best choice (alternative), which corresponds to the multimodal transportation "Truck-Train".

\section{Conclusions}

The methodology for solving the vehicles selection problem in multimodal transportation under multicriteriality, and uncertainty has been proposed in this paper. This technique is based on the BOCR method, and takes into account a number of qualitative indicators that determine the optimality and efficiency of cargo transportation.

To aggregate individual expert assessments, a procedure has been proposed that allows to synthesize a group decisions taking into account 
various forms of experts' preferences presentation (interval, fuzzy, crisp judgments). This approach allows to model various forms of "ignorance" (uncertainty, inconsistency, incompleteness, fuzziness, etc.) under the influence of which experts' judgments are formed, and not to impose strict restrictions on the form of their presentation.

\section{Список литературы:}

1. Aguarón J. The geometric consistency index: Approximated thresholds / J. Aguarón, J. M. Moreno-Jiménez // European Journal of Operational Research. 2003. - Vol. 147. - No. 1. - Pp. 137-145. doi:10.1016/S0377-2217(02)00255-2

2. Айбазова С.Х. Оптимизация системы логистики в бизнесе на основе теоретико-игровой модели: диссертация на соискание ученой степени кандидата экономических наук / С.X. Айбазова - М. : Финансовый университет при Правительстве РФ, 2014. - 154 с.

3. Алесинская Т.В. Основы логистики. Функциональные области логи-стического управления / Т.В. Алесинская - Таганрог : ТТИ ЮФУ, 2010. - 116 с.

4. Bulut E. Use of consistency index, expert prioritization and direct numerical inputs for generic fuzzy-AHP modeling: a process model for shipping asset management / E. Bulut, O. Duru, T. Keçeci, S. Yoshida // Expert Systems with Applications. - 2012. Vol. 39. - No. 2. - Pp. 1911-1923. doi:10.1016/j.eswa.2011.08.056

5. Chang D.Y. Extent analysis and synthetic decision, optimization tech-niques and applications / D.Y. Chang // World Scientific. - 1992. - Vol. 1. - P. 352.

6. Demirel T. Fuzzy Analytic Hierarchy Process and its application / T. Demirel, N. Ç. Demirel, C. Kahraman - In: C. Kahraman (eds) Fuzzy Multi-Criteria Decision Making. Springer Optimization and Its Applications, vol. 16. - Boston : Springer, 2008. - Pp. 53-83.

7. Dempster A.P. Upper and lower probabilities induced by a muilti-valued mapping / A. P. Dempster // Annals of Mathematical Statistics. - 1967. - Vol. 38. No. 2. - Pp. 325-339.

8. Dopazo E. A parametric model for determining consensus priority vectors from fuzzy comparison matrices / E. Dopazo, K. Lui, S. Chouinard, J. Guisse // Fuzzy Sets and Systems. - 2013. - Vol. 246. - Pp. 49-61. doi:10.1016/j.fss.2013.07.022

9. Гончарук С.М. Методологические основы проектирования этапного развития облика и мощности мультимодальной транспортной сети / С.М. Гончарук - Хабаровск : ДВГУПС, 2012. - 227 с.

10. Kulak O. Fuzzy multi-attribute selection among transportation companies using axiomatic design and analytic hierarchy process / O. Kulak, C. Kahraman // Information Sciences. - 2005. - Vol. 170. - Pp. 191-210. doi: 10.1016/j.ins.2004.02.021

11. Никифоров В.С. Мультимодальные перевозки и транспортная логистика / В.С. Никифоров - М. : ТрансЛит, 2007. - 272 с.

12. Плоткин Б.К. Экономико-математические методы и модели в логи-стике / Б.К. Плоткин - Спб. : СпбГУЭФ, 2010. - 96 с. 
13. Саати Т. Принятие решений при зависимостях и обратных связях: Аналитические сети / Т. Саати; под. ред А.В. Андрейчиков, О.М. Андрейчикова. - М. : ЛКИ, 2008. - 360 с.

14. Saaty T. The Analytic Hierarchy Process: panning, priority setting, resource allocation. Front cover / T. Saaty - New York : McGraw Hill, 1980. - 287 p.

15. Sentz K. Combination of evidence in Dempster-Shafer theory / K. Sentz, S. Ferson. - Albuquerque : Sandia National Laboratories, 2002. - 94 p.

16. Shafer G. A mathematical theory of evidence / G. Shafer. - Princeton : Princeton University Press, 1976. - 297 p.

17. Smarandache F. Advances and applications of DSmT for information fusion (collected works) 1 / F. Smarandache, J. Dezert. - Rehoboth : American Research Press, 2004. -438 p.

18. Smarandache F. Advances and applications of DSmT for information fusion (collected works) 21 / F. Smarandache, J. Dezert. - Rehoboth : American Research Press, 2006. $-461 \mathrm{p}$.

19. Sugihara K. Interval priorities in AHP by interval regression analysis / K. Sugihara, H. Ishii, H. Tanaka // European Journal of Operational Research. 2004. - Vol. 158. - No. 3. - Pp. 745-754. doi: 10.1016/S0377-2217(03)00418-1

20. Wang Y.M. A two-stage logarithmic goal programming method for generating weights from interval comparison matrices / Y.M. Wang, J.B. Yang, D.L. Xu // Fuzzy Sets and Systems. - 2005a. - Vol. 152. - Pp. 475-498. doi:10.1016/j.fss.2004.10.020

21. Wang Y.M. Interval weight generation approaches based on consistency test and interval comparison matrices / Y.M. Wang, J.B. Yang, D.L. Xu // Applied Mathematics and Computation. - 2005b. - Vol. 167. - Pp. 252-273. doi:10.1016/j.amc.2004.06.080

22. Wang Y.M. A goal programming method for obtaining interval weights from an interval comparison matrix / Y.M. Wang, T.M.S. Elhag // European Journal of Operational Research.-2007.-Vol. 177.-Pp. 458-471. doi:10.1016/j.ejor.2005.10.066

\section{References:}

1. Aguarón J., Moreno-Jiménez J.M. (2003). The geometric consistency index: Approximated thresholds. European Journal of Operational Research, vol. 147, no. 1, pp. 137-145. doi: 10.1016/S0377-2217(02)00255-2

2. Aybazova S.Kh. (2014). Optimizatsiya sistemy logistiki v biznese na osnove teoretiko-igrovoy modeli [Optimization of a logistics system in business based on a game-theoretic model] (PhD Thesis). Moscow: Finansovyy universitet pri Pravitel'stve RF. (in Russian)

3. Alesinskaya T.V. (2010). Osnovy logistiki. Funktsional'nye oblasti logi-sticheskogo upravleniya [Basics of logistics. Functional areas of logistics management. Taganrog: TTI YuFU. (in Russian)

4. Bulut E., Duru O., Keçeci T., Yoshida S. (2012). Use of consistency index, expert prioritization and direct numerical inputs for generic fuzzy-AHP modeling: a process model for shipping asset management. Expert Systems with Applications, vol. 39, no. 2, pp. 1911-1923. doi: 10.1016/j.eswa.2011.08.056

5. Chang D.Y. (1992). Extent analysis and synthetic decision, optimization techniques and applications. World Scientific, vol. 1, p. 352. 
6. Demirel T., Demirel N.Ç., Kahraman C. (2008). Fuzzy Analytic Hierarchy Process and its application. In: C. Kahraman (eds) Fuzzy Multi-Criteria Decision Making. Springer Optimization and Its Applications, vol. 16. Boston: Springer, pp. 53-83.

7. Dempster A.P. (1967). Upper and lower probabilities induced by a muiltivalued mapping. Annals of Mathematical Statistics, vol. 38, no. 2, pp. 325-339.

8. Dopazo E., Lui K., Chouinard S., Guisse J. (2013). A parametric model for determining consensus priority vectors from fuzzy comparison matrices. Fuzzy Sets and Systems, vol. 246, pp. 49-61. doi: 10.1016/j.fss.2013.07.022

9. Goncharuk S.M. (2012). Metodologicheskie osnovy proektirovaniya etapnogo razvitiya oblika $i$ moshchnosti mul'timodal'noy transportnoy seti [Methodological aspects for designing the staged development of the appearance and power of a multimodal transport network]. Khabarovsk: DVGUPS. (in Russian)

10. Kulak O., Kahraman C. (2005). Fuzzy multi-attribute selection among transportation companies using axiomatic design and analytic hierarchy process. Information Sciences, vol. 170, pp. 191-210. doi: 10.1016/j.ins.2004.02.021

11. Nikiforov V.S. (2010). Mul'timodal'nye perevozki i transportnaya logistika [Multimodal transport and transport logistics]. Moscow: TransLit. (in Russian)

12. Plotkin B.K. (2010). Ekonomiko-matematicheskie metody $i$ modeli $v$ logistike [Economic and mathematical methods and models in logistics]. St. Petersburg: SpbGUEF. (in Russian)

13. Saati T. (2008). Prinyatie resheniy pri zavisimostyakh i obratnykh svyazyakh: Analiticheskie seti [Decision making under dependencies and feedbacks: Analytic networks]. In A.V. Andreychikov, O.M. Andreychikova (eds). Moscow: LKI. (in Russian)

14. Saaty T. (1980). The Analytic Hierarchy Process: panning, priority setting, resource allocation. Front cover. New York: McGraw Hill.

15. Sentz K., Ferson S. (2002). Combination of evidence in Dempster-Shafer theory. Albuquerque: Sandia National Laboratories.

16. Shafer G. (1976). A mathematical theory of evidence. Princeton: Princeton University Press.

17. Smarandache F., Dezert J. (2004). Advances and applications of DSmT for information fusion (collected works), 1. Rehoboth: American Research Press.

18. Smarandache F., Dezert J. (2006). Advances and applications of DSmT for information fusion (collected works), 2. Rehoboth: American Research Press.

19. Sugihara K., Ishii H., Tanaka H. (2004). Interval priorities in AHP by interval regression analysis. European Journal of Operational Research, vol. 158, no. 3, pp. 745-754. doi: 10.1016/S0377-2217(03)00418-1

20. Wang Y.M., Yang J.B., Xu D.L. (2005a). A two-stage logarithmic goal programming method for generating weights from interval comparison matrices. Fuzzy Sets and Systems, vol. 152, pp. 475-498. doi: 10.1016/j.fss.2004.10.020

21. Wang Y.M., Yang J.B., Xu D.L. (2005b). Interval weight generation approaches based on consistency test and interval comparison matrices. Applied Mathematics and Computation, vol. 167, pp. 252-273. doi: 10.1016/j.amc.2004.06.080

22. Wang Y.M., Elhag T.M.S. (2007). A goal programming method for obtaining interval weights from an interval comparison matrix. European Journal of Operational Research, vol. 177, pp. 458-471. doi: 10.1016/j.ejor.2005.10.066 